\title{
Troca e relação na estética relacional
}

\section{Manoel Silvestre Friques}

\section{Resumo}

0 presente artigo propõe uma reflexão a respeito da estética relacional, desenvolvida na década de 1990 pelo crítico e curador francês Nicolas Bourriaud. Para tal, elege-se como contraponto o pensamento de Marcel Mauss, especificamente seu ensaio sobre a dádiva, a fim de se perceber as semelhanças e diferenças entre as abordagens dos dois autores para os conceitos de relação e de troca. A indagação que motiva este texto é assim elaborada: os modelos de sociabilidade propostos por Bourriaud reforçam e reproduzem a lógica do capitalismo de consumo ou lhe sugerem alternativas?

\section{Palavras-Chave}

Estética Relacional. Arte Contemporânea. Modelos de Sociabilidade. Sociologia da Arte.

Manoel Silvestre Friques I manoel.friques@gmail.com Mestre em Artes Cênicas pela Universidade Federal do Estado do Rio de Janeiro (UNIRIO). Doutorando no Programa de História Social da Cultura pela Pontifícia Universidade Católica do Rio de Janeiro (PUCRio). Professor da Escola de Engenharia de Produção da Universidade Federal do Estado do Rio de Janeiro (UNIRIO).

\section{Introdução}

Em meio à exibição de fotos da École Nationale Supérieure des Beaux-Arts - Instituição da qual fora designado diretor havia poucos meses - Nicolas Bourriaud ${ }^{1}$ comentou brevemente que havia uma aproximação entre sua estética relacional e a sociologia. Não foi informada, no entanto, a natureza de vínculo que sua formulação teórica, que tem no livro homônimo publicado em 1998 a sua principal fundamentação, estabeleceria com tal campo do saber. 0 conjunto de obras e artistas analisados por Bourriaud configurariam uma arte sociológica - seja lá a que tal expressão possa se referir - ou seu estudo se inscreveria em uma sociologia da arte? De todo modo, o breve comentário suscitou a possibilidade de se buscar um entendimento da estética relacional sob uma perspectiva específica das ciências sociais: o conceito de dádiva desenvolvido por Marcel Mauss em seu Ensaio sobre a dádiva - forma e razão da troca nas sociedades arcaicas. A ênfase dada aos conceitos de relação e troca tanto por parte de Bourriaud quanto por parte 
de Mauss - motivou o presente artigo, operando como prisma analítico para a reflexão a seguir.

\section{A Estética Relacional}

Ao justificar o surgimento da estética relacional - sendo esta específica à arte dos anos 1990 -, Bourriaud esboça o seguinte quadro histórico geral:

Essa história [da arte], hoje, parece ter tomado um novo rumo: depois do campo das relações entre Humanidade e divindade, a seguir entre Humanidade e objeto, a prática artística agora se concentra na esfera das relações inter-humanas, como provam as experiências em curso desde o começo dos anos 1990 (BOURRIAUD, 2009, p. 39-40).

Note-se que tal quadro é marcado por uma

lógica sequencial, na qual o "caráter relacional intrínseco da obra de arte" (BOURRIAUD, 2009, p. 39-40) desloca paulatinamente o seu foco até, por fim, repousar na esfera das relações humanas.

Sem nos atermos ao modelo historiográfico adotado pelo autor, observemos apenas que este, caracterizado por fases que se sucedem e/ ou substituem, parece encontrar suas raízes em uma lógica teleológica, progressiva e, por isso, próxima à narrativa mestra que Arthur Danto havia dado como encerrada na década de 1960. Ao lado disso, observa-se que a estética relacional não representa a presença da relação na arte em contraposição a sua ausência nas criações artísticas anteriores. 0 caráter relacional é inerente à obra de arte. A diferença crucial entre a produção artística de outrora e a produzida a partir dos anos 1990 reside na ênfase que a segunda concede a um tipo específico de relação, a saber, as experiências inter-humanas. Mas o que, de fato, significa isso?

Significa dizer que a produção artística dos últimos 20 anos procura criar, em museus e galerias, modelos de sociabilidade nos quais 0 espectador deve participar ativamente. $\mathrm{Na}$ realidade, os artistas não criam tais modelos mas, como DJs e internautas, se apropriam de elementos pré-existentes e os deslocam para os espaços de arte. Trata-se de uma arte da pósprodução, assim definida por Bourriaud em livro que é a continuação de sua estética relacional:

A prática do DJ, a atividade do internauta, a atuação dos artistas da pós-produção supõem uma mesma figura do saber, que se caracteriza pela invenção de itinerários por entre a cultura. 0s três são semionautas que produzem, antes de mais nada, percursos originais entre os signos (BOURRIAUD, 2009b, p. 14).

Como um "semionauta", 0 artista contemporâneo se baseia em modelos de sociabilidade encontrados no dia a dia - jantares, festas, encontros, contratos, trocas comerciais etc. - e

Em 2012, Bourriaud esteve no Rio de Janeiro para duas palestras: a primeira se deu na PUC-Rio em 13 de abril e teve como tema "As escolas de Arte no século XXI"; a segunda, cujo título era "Radicante, por uma estética da globalização", ocorreu no MAM no dia seguinte. Participei do primeiro encontro no qual o curador francês nos informou a respeito de seu novo cargo: diretor da École Nationale Supérieure des Beaux-Arts, em Paris. 
os reformula no contexto de uma galeria de arte. Tais propostas têm como justificativa a necessidade de resposta à uniformização dos comportamentos e à padronização do vínculo social em meio ao caos cultural atual. A estética relacional seria a saída contra a previsão de Bourriaud, para quem "em breve, as relações humanas não conseguirão se manter fora dos espaços mercantis" (BOURRIAUD, 2009, p. 12).

0 inimigo, portanto, é claro: a reificação das relações humanas. Contra esta tendência de mercantilização do vínculo social, um conjunto específico de $\operatorname{artistas}^{2}$ trataria de criar interstícios sociais, entendidos como um "espaço de relações humanas que, mesmo inserido de maneira mais ou menos aberta e harmoniosa no sistema global, sugere outras possibilidades de troca além das vigentes nesse sistema" (BOURRIAUD, 2009, p. 22, grifo nosso). A exposição, com isso, torna-se um interstício no qual uma determinada coletividade será constituída de modo efêmero. As obras de arte não são, portanto, produtos, mas momentos de sociabilidade. Um "domínio de trocas" particular é instituído a partir das instruções, ou dos objetos produtores de sociabilidade, propostos pelo artista. Mas de que forma tais domínios são alternativos às trocas comerciais (e aqui se chega a um dos pontos nevrálgicos deste texto)?
0 argumento de Bourriaud tem por base uma ênfase nas relações humanas, em especial nas trocas entre indivíduos, como forma de constituição de sociabilidades. Resta-nos perguntar de que modo isso é feito, a partir da descrição e da análise de algumas experiências produzidas por artistas mencionados pelo crítico francês. Antes, porém, de analisarmos algumas criações de Rirkrit Tiravanija - artista tailandês considerado 0 expoente da estética relacional - e Carsten Höller, passemos à compreensão das relações e da troca sob um ponto de vista sociológico específico, de Marcel Mauss. A hipótese que nos leva a realizar esta passagem é a seguinte: a dádiva, enquanto forma arcaica da troca, impõe limites precisos à abordagem de Bourriaud, permitindo o desenvolvimento de um discurso crítico em relação às noções elaboradas pelo autor.

\section{A troca-dádiva}

Em seu "trabalho mais justamente célebre e aquele de influência mais profunda" (LEVISTRAUSS, 2003, p. 23), Mauss debruça-se sobre as formas arcaicas da troca encontradas em diversas sociedades, em especial, nos melanésios, polinésios e americanos. ${ }^{3} \mathrm{~A}$ dádiva-troca apresenta um conjunto de obrigações como elementos característicos: obrigação de dar, obrigação de receber e obrigação de retribuir. Se a primeira é

Rirkrit Tiravanija, Vanessa Beecroft, Douglas Gordon, Andrea Zittel, Angela Bulloch, Gabriel Orozco, Liam Gillick, Dominique Gonzalez-Foerster, Jorge Pardo, Phillipe Parreno, Maurizio Cattelan, Jes Brinch, Christine Hill, Carsten Höller, Noritoshi Hirakawa, Pierre Huyghe e Felix Gonzalez-Torres são os nomes recorrentes na exposição de Bourriaud.

Mauss observa também os costumes da dádiva nos direitos romano muito antigo, hindu, germânico, céltico e chinês. 
a "essência do potlatch" (MAUSS, 2003, p. 243), a última o é plenamente ("é todo o potlatch") (MAUSS, 2003, p. 249). Dar, neste contexto, é a maneira pela qual um chefe conserva a autoridade sobre a sua tribo: "ele não pode provar essa fortuna a não ser gastando-a, distribuindo-a, humilhando com ela os outros, colocando-os 'à sombra de seu nome"” (MAUSS, 2003, p. 244). Percebe-se neste ponto um aspecto que diferencia a dádiva-troca da troca comercial: no sistema de prestações e contraprestações que é o potlatch, em casos extremos, o prestígio a ser conservado pelo chefe e seu clã obriga, não a manutenção da riqueza, mas a sua destruição completa. "É uma disputa", observa Mauss (2003, p. 238), "de quem será o mais rico e também o mais loucamente perdulário".

Quando uma dádiva é oferecida, não se pode recusá-la. A rejeição representa a incapacidade de retribuição, a aceitação de uma desigualdade e, consequentemente, uma espécie de nivelamento e perda de prestígio e autoridade. A obrigação em receber é também um comprometimento: "recebe-se uma dádiva como 'um peso nas costas'. Faz-se mais do que se beneficiar de uma coisa e de uma festa, aceitouse um desafio" (MAUSS, 2003, p. 248). Tal desafio conduz inevitavelmente à terceira obrigação, a retribuição, que surge quando o donatário recebe a dádiva com espírito de reciprocidade.

Dois elementos conexos permeiam as três obrigações acima: a rivalidade e 0 risco. Para explicar tais presenças, convém esclarecer que a dádiva-troca ocorre entre clãs, tribos, famílias, em suma, coletividades. As trocas são realizadas entre pessoas morais e envolvem, a todo o momento, 0 risco de perda de autoridade, honra e prestígio. Há, com isso, sempre um conflito latente na dádiva que pode vir a resultar, caso as obrigações voluntárias não sejam realizadas, em combate: "recusar dar, negligenciar convidar, assim como recusar receber, equivale a declarar guerra; é recusar a aliança e a comunhão" (MAUSS, 2003, p. 202).

0 trio de obrigações que configura a dádivatroca constitui a base do potlatch, mencionado anteriormente e definido como um gênero de instituição específico, chamado de prestações totais de tipo agonístico. Um sistema de prestações totais é, por sua vez, um regime de trocas que possui as características descritas acima e no qual não se trocam coisas úteis economicamente, mas

[...] amabilidades, banquetes, ritos, serviços militares, mulheres, crianças, danças, festas, feiras, dos quais o mercado é apenas um dos momentos, e nos quais a circulação de riquezas não é senão um dos termos de um contrato bem mais geral e permanente (MAUSS, 2003, p. 191).

Tais sistemas são observados em fatos sociais totais (ou gerais), assim denominados por colocar em ação a "totalidade da sociedade e suas instituições" (MAUSS, 2003, p. 309). A mistura é o elemento crucial destes: todas as instituições, sejam elas religiosas, morais, econômicas ou jurídicas, se revelam nestes 
fatos complexos. Esta mistura também faz coincidirem pessoas e coisas e, neste ponto, vale recorrer, uma vez mais, à voz de Mauss (2003, p. 212):

Trata-se, no fundo, de misturas. Misturam-se as almas nas coisas, misturam-se as coisas nas almas. Misturam-se as vidas, e assim as pessoas e as coisas misturadas saem cada qual de sua esfera e se misturam: 0 que é precisamente o contrato e a troca.

Se a forma arcaica da troca já foi aqui descrita, a razão de sua existência pode ser compreendida a partir da mistura das almas nas coisas e das coisas nas almas. Mais acima, observou-se a presença do risco da perda de autoridade e prestígio: trata-se de uma preocupação moral transversal à dádiva-troca diretamente associada ao espírito da coisa dada, à força das coisas dadas que constrangem o donatário a retribuí-las. 0 mana (hau) deve ser entendido como uma virtude - não uma propriedade física dos bens trocados - mas uma espécie de fonte de energia (a "personalidade da coisa") que funciona como eixo deste sistema de trocas.

A troca não é, portanto, realizada no interior de um sistema de compra e movida por um interesse individual utilitarista, mas por meio de dádivas feitas e retribuídas, motivadas pelo mana. A mistura inerente à este sistema é aquilo que marca também o regime social, configurando-lhe um permanente movimento contínuo que atravessa a vida social e também lhe é seu símbolo:
Tudo se conserva e tudo se confunde; as coisas têm uma personalidade e as personalidade são, de certo modo, coisas permanentes do clã. Títulos, talismãs, cobres e espíritos dos chefes são homônimos e sinônimos, de mesma natureza e mesma função. A circulação, dos bens acompanha a dos homens, das mulheres e das crianças, dos festins, dos ritos, das cerimônias e das danças, mesmo a dos gracejos e das injúrias. No fundo, ela é a mesma. Se coisas são dadas e retribuídas, é porque se dão e se retribuem 'respeitos'" - podemos dizer igualmente 'cortesias'. Mas é também porque as pessoas se dão ao dar, e se as pessoas se dão, é porque se 'devem' - elas e seus bens - aos outros (MAUSS, 2003, p. 263, grifos do autor).

\section{A troca na estética relacional}

Na conclusão de seu ensaio, Mauss estabelece nitidamente uma diferença entre a forma-dádiva e 0 regime de compra e venda. Neste momento de sua argumentação, o autor esforça-se por observar vestígios - ou mais do que isso - deste tipo arcaico de troca em nossas sociedades. Talvez não possa encontrá-lo plenamente, mas não se abstém de dizer que a moral constituinte da dádiva e que se traduz em sua forma tripla de obrigação motivada pelo mana (a alma da coisa) reaparece em algumas sociedades, correspondendo, inclusive, a um "retorno ao direito". De fato, são os velhos princípios que, em nossos dias, reagem às abstrações, inumanidades e rigores de nossos códigos (MAUSS, 2003, p. 295).

Assim, a "atmosfera em que dádiva, obrigação e liberdade se misturam" não está apenas distante de nós, em sociedades arcaicas. Ela se estende 
a nossas vidas e é a partir desta extensã $0^{4}$ que devemos retomar o trabalho de Bourriaud. Deve estar claro que o objetivo aqui não é verificar se a estética relacional se adequa ou não ao sistema de trocas descrito por Mauss. Neste caso a resposta seria uma só: não. Estas duas abordagens da troca são aproximadas a partir das desconfianças e questionamentos que ambos os autores fazem em relação ao regime econômico utilitarista: se em Mauss ele se contrapõe à economia da dádivatroca, em Bourriaud ele se torna o responsável pela mercantilização das relações humanas.

Para que a aproximação proposta seja realizada, faz-se necessário recorrer a algumas experiências da estética relacional, a fim de verificar a sua lógica e funcionamento. Neste ponto, um esclarecimento: a noção de Bourriaud não é um programa estético, nem se configura como um manifesto definidor de uma identidade estável de um grupo de artistas. Trata-se de uma aventura teórica cuja fundamentação está no trabalho de um conjunto específico de criadores como Rirkrit Tiravanija, Vanessa Beecroft, Douglas Gordon, Andrea Zittel, Gabriel Orozco, Liam Gillick, Dominique GonzalezFoerster, Phillipe Parreno, Maurizio Cattelan, Carsten Höller, Pierre Huyghe e Felix GonzalezTorres, para ficar nos nomes mais recorrentes. As criações produzidas por esta amostra de artistas são as mais diversas e, surpreendentemente, ocupam poucas páginas do livro de Bourriaud. Com exceção de análises breves e pontuais, a menção aos trabalhos, a despeito da disponibilidade de informações sobre eles, vem desprovida de descrições e investigações a respeito de sua forma, moral e razão, para colocar nos termos de Mauss. Há, com isso, uma diferença crucial quanto ao rigor metodológico que move os dois escritos. Se Mauss se debruça sobre os fatos sociais, observando concretamente a vida social em uma descrição por vezes exaustiva das dinâmicas que caracterizam as formas arcaicas da troca, Bourriaud apressase por uma generalização da condição artística contemporânea, sem que isso venha acompanhado de convincentes e fundamentadas análises.

Desse modo, a estética relacional institui um domínio de trocas, insuficientemente descrito para que se possa perceber as linhas gerais, e fundamentais, de seu funcionamento. Na tentativa de vislumbrar tais forma e razão, recorre-se, neste artigo, a produções artísticas de dois expoentes da estética relacional: Rirkrit Tiravanija e Carsten Höller. Antes, porém, convêm não cometer injustiças e comentar o capítulo dedicado à obra de Felix Gonzalez-Torres. ${ }^{5} 0$ artista cubano é considerado uma espécie de precursor da

No que concerne à nossa distância temporal em relação às sociedades arcaicas, vale lembrar, conforme Argan (2003, p. 21), que a pré-história não possui limites cronológicos precisos.

Felix Gonzalez-Torres (1957-1996) foi um artista cubano, naturalizado americano. Co-presença e disponibilidade: a herança teórica de Felix Gonzalez-Torres é o único ensaio dedicado a um artista em Estética Relacional. Em Pós-produção, no capítulo Uso das formas, são realizadas análises breves, porém mais detidas, sobre alguns criadores. De um modo geral, o olhar de Bourriaud para as obras é cuidadoso, porém tais estudos parecem funcionar mais como análises críticas isoladas do que fundamentações da tese do autor, para quem a arte é marcada pela estética relacional e/ou pela pós-produção. 
estética relacional, pois sua obra cria um "espaço baseado na intersubjetividade, que é precisamente 0 que será explorado pelos artistas mais interessantes [mencionados acima] da década seguinte [anos 1990]" (BOURRIAUD, 2009, p. 72). A tese do autor é que a homossexualidade em Gonzalez-Torres não se reduz apenas ao horizonte temático de suas obras, ${ }^{6}$ constituindo, sobretudo, o seu aparato formal. Trata-se de uma dualidade sem oposições que prevê um encontro, uma vida em comum, uma coabitação. Perfect Lovers é elucidativo do argumento acima: dois relógios iguais, dispostos lado a lado e parados exatamente na mesma hora evocam, mais do que uma sincronia, uma perfeita sintonia.

Se os trabalhos acima são analisados pela perspectiva de uma perfeita coabitação, são em obras como Untitled (Portrait of Ross in L.A.), 1991, e Untitled (Blue Mirror), 1990, que pode ser observada uma forma específica de troca. No primeiro caso, oitenta quilos de balas estão dispostos no canto da sala de uma galeria, disponíveis aos visitantes. Ross, namorado de Gonzalez-Torres, morrera de AIDS e a quantidade de balas corresponde ao peso ideal do companheiro saudável. Com 0 tempo, a instalação tende a desvanecer em um movimento paralelo ao enfraquecimento e posterior desaparecimento de Ross. Em Blue Mirror, uma pilha de papel azul, igualmente disponível ao visitante, é disposta na galeria.
0 risco de sua dissipação é semelhante. Em ambos os casos, o visitante, ao optar por levar consigo a unidade constituinte da instalação, participa do próprio aniquilamento da obra de arte. Ele leva uma parte da obra e, ao fazer isso, a torna incompleta e cada vez mais próxima de seu momento de extinção. Em Portrait of Ross, 0 ato se reveste, inclusive, de uma dimensão alegórica pois cada bala é uma parte do corpo do companheiro, sendo a sua debilidade associada à desmaterialização da instalação.

Tais obras, sem dúvida alguma, não são fatos complexos movidos por uma dádiva-troca. Não estão comprometidas pessoas morais, mas indivíduos, tampouco abalam a autoridade de nenhuma das partes envolvidas. 0 conflito existente em tais obras se dá pelo objeto simbólico que cada visitante pode se apropriar sem, no entanto, haver obrigatoriamente 0 espírito de reciprocidade. Talvez nem a obrigação em dar ou em receber possam ser vistas, pois o que existe é a disponibilidade gratuita de elementos (balas, folhas de papel etc.) que podem, ou não, ser tomados pelo visitante. Não aceitá-la não significa perda de autoridade e a obra de arte, que desaparece materialmente, na realidade sempre se renova, pois as quantidades são repostas periodicamente (do exato modo como Gonzalez-Torres prescreveu). 
A oferta de alimentos também caracteriza algumas manifestações artísticas do tailandês Rirkrit Tiravanija. Untitled (Free/Still), de 1992, é o trabalho que muitos consideram como o marco de sua carreira: 0 artista fez da galeria de arte (303 Gallery, Nova York) um espaço de convívio, no qual cozinhou e ofereceu aos visitantes, gratuitamente, uma receita tailandesa de arroz com curry. Assim como as obras acima comentadas de GonzalezTorres, em Free, o visitante está livre para aceitar a oferta do artista, porém sem haver o risco de desaparecimento da obra. Neste caso, Tiravanija, além de oferecer algo palpável (a comida) constrói também um lugar de convivência que reúne e aglutina os participantes. A obra de arte funciona, com isso, como um pretexto para que as pessoas possam interagir umas com as outras. Mais do que aceitar 0 alimento, um indivíduo deve se relacionar com os demais: este é o propósito do trabalho, cuja experiência foi assim relatada por Jerry Saltz (apud BISHOP, 2012, p. 122):

$\mathrm{Na} 303$ Gallery eu geralmente me sentava com alguém ou era acompanhado por algum desconhecido e era ótimo. A galeria virou um lugar para compartilhar, um lugar alegre para conversar com sinceridade. Tive maravilhosas rodadas de refeições com galeristas. Uma vez Paula Cooper e eu comemos juntos e ela recontou um pedaço longo e complicado de uma fofoca profissional. Outro dia, Lisa Spellman relatou em detalhes hilariantes a história de uma intriga sobre um colega galerista que tentava, sem sucesso, roubar um de seus artistas. Mais ou menos uma semana depois David Zwirner me acompanhou. Encontrei-o por acaso na rua e ele disse "nada está dando certo hoje, vamos ao Rirkrit". Nós fomos e falamos sobre a falta de emoção no mundo da arte novaiorquino. Outra vez fui acompanhado por Gavin Brown, 0 artista e galerista... que falou do colapso do $\mathrm{SoH}_{0}$ - só para considerá-lo bem vindo e dizer que já era hora porque as galerias andavam mostrando muita arte medíocre. Em outro momento uma mulher não identificada me acompanhou e um clima de paquera curiosa pairava no ar. E teve ainda uma outra vez conversei com um jovem artista que morava no Brooklin e tinha tido verdadeiros insights sobre as mostras que tinha acabado de ver.

0 depoimento de Saltz, rotulado por Claire Bishop de "tagarelice informal", revela precisamente a natureza das experiências propostas por Tiravanija. Se a galeria se transforma em um espaço de convívio no qual os indivíduos podem se reunir e interagir, o "domínio de trocas" instituído ali é entre galeristas e apreciadores de arte, em uma atmosfera de bar que permite com que se façam contatos profissionais. Nada mais adequado ao mercado de arte, portanto. Mesmo que 0 alimento seja compartilhado (e aí respeita-se a sua natureza) $)^{7}$ ele 0 é em um contexto em que as relações humanas motivadas por esta partilha tratam de confirmar a ideia de "comunidade cujos membros identificam-se uns com os outros porque têm algo em comum": 0 interesse pela arte que se traduz em fofocas, conversas sobre exposições e paquera (BISHOP, 2012). 
Uma possível contra-argumentação à posição de

Bishop associaria a oferta de comida thai realizada por Tiravanija às refeições de cerimônia descritas por Lévi-Strauss. Afinal de contas, 0 que 0 artista tailandês faz é "dar uma recepção". 0 arroz, por sua vez, é um alimento que possui para os tailandeses dupla importância - sagrada e econômica -, fato que faz com que a oferta do artista adquira um "sabor especial". Na cozinha tailandesa, entretanto, 0 arroz nunca está ausente. Além disso, a receita de Tiravanija configura-se propriamente como um "menu cotidiano", distanciando-se, com isso, das rich food que caracterizam as refeições de cerimônia. Apesar disso, Free propõe uma situação em que estranhos se encontram, havendo aquela tensão entre "a norma da solidão e 0 fato da sociedade" (LÉVI-STRAUSS, 1982, p. 99). A tagarelice informal não confirma, todavia, um encontro entre desconhecidos, muito pelo contrário. A possibilidade de se instaurar um ambiente hostil parece estar fora do espaço da galeria: em seu interior, deve-se, livre e compulsoriamente, praticar a cordialidade entre os pares, pois tudo é "ótimo", "alegre", "maravilhoso".

0 último caso aqui mencionado é semelhante: as obras Carrossel (1999) e Valério I e II (1998) de Carsten Höller. Nestes trabalhos, 0 artista belga instala na galeria de arte um carrossel e um escorregador, respectivamente. Brinquedos encontrados em parques de diversões são, portanto, deslocados para o espaço de uma galeria de arte. Exibido na $28^{\text {a }}$ Bienal de São Paulo, Valério I e II causou imenso rebuliço entre os frequentadores, minimizando a tensão provocada pelo segundo andar vazio do evento. Em entrevista à curadora Ana Paula Cohen, Höller afirma que "não dá, já é tarde demais" para mudar a lógica de consumo que fez com que 0 sistema de arte contemporânea se tornasse comparável a eventos de massa, como grandes festivais de indústrias do entretenimento. Se a mudança não é viável, resta transformar literalmente 0 espaço de exibição em um parque de diversões. Do ponto de vista de quem recebe a experiência proposta, há, como no caso de Tiravanija, um conforto sereno, sem antagonismos. Em outras palavras, beneficiamonos da festa sem o risco da guerra; aceitamos 0 alimento e a diversão, sem desafios.

A ausência de conflito nas propostas artísticas levadas em conta neste $\operatorname{artig}_{0}{ }^{9}$ é 0 indicador que mais parece colocar em xeque a tentativa da estética relacional de construir um espaço

É curioso o fato desta obra de Tiravanija - Free - possuir o mesmo título de um livro recente de Chris Anderson. Em sua obra, este autor defende a ideia de que as empresas podem conquistar mais receitas se oferecem os produtos aos clientes e não cobram, a exemplo da internet. Para ele, estamos em um momento histórico no qual a economia pode ser construída em torno da ideia do "grátis". A relação entre a exposição e um livro que divulga uma nova estratégia de negócios constata que Bourriaud se esforça em criar uma leitura da produção artística totalmente aderente à realidade de consumo contemporânea. A figura do semionauta realiza, por exemplo, uma perfeita identidade entre 0 artista e este personagem do consumo tecnológico que é 0 internauta.

0 trabalho de Gonzalez-Torres parece escapar a este diagnóstico. Aquilo que desperta interesse em sua obra não é motivado, no entanto, pela estética relacional. 0 mesmo pode ser dito para produções de Vanessa Beecroft, Gabriel Orozco, Maurizio Cattelan e Pierre Huyghe. 
alternativo às trocas instituídas. ${ }^{10}$ Assim, se esta está baseada na esfera das relações interhumanas, há que se perguntar que tipo de relação os artistas e suas obras criam para o público. A participação de frequentadores, e sua perfeita comunhão, está mais próxima de imagens de massas do que uma comunidade preocupada com a sua constituição e validade. A descrição de obras produzidas por ícones do "movimento" como Höller e Tiravanija nos permite vislumbrar que, por mais que espaços de convívio sejam propostos, os "domínios de troca" mais reforçam e reproduzem a lógica do capitalismo de consumo do que resistem ou propõem alternativas a ela. Se já é tarde demais, talvez valha a pena recorrer, uma última vez, a Mauss (2003, p. 299), para quem "essa moral [que faz com que 0 cidadão tenha um senso agudo de si mesmo, dos outros e da realidade social] é eterna".

\section{Referências}

ARGAN, Giulo Carlo. História da Arte Italiana 1: da Antiguidade a Duccio. São Paulo: Cosac e Naify, 2003. BISHOP, Claire. Antagonismo e estética relacional. Revista Tatuí, n. 12, 2012. Disponível em: < http:// revistatatui.com/secao/revista/tatui-12/>. Acesso em: 23 jun. 2012. Originalmente publicado na revista October, n. 110, 2004.

BOURRIAUD, Nicolas. Estética relacional. São Paulo: Martins Fontes, 2009a.

BOURRIAUD, Nicolas. Pós-produção: como a arte reprograma o mundo contemporâneo. São Paulo: Martins Fontes, 2009b.

DANTO, Arthur C. Após o fim da arte: arte contemporânea e os limites da história. São Paulo: Odysseus Editora, 2006.

HÖLLER, Carsten. Entrevista a Ana Paula Cohen. 28. Bienal de São Paulo: guia. São Paulo: Fundação Bienal de São Paulo, 2008.

JAMESON, Fredric. Virada cultural: reflexões sobre o pós-modernismo. Rio de Janeiro: Civilização Brasileira, 2006.

LÉVI-STRAUSS, Claude. As estruturas elementares do parentesco. Petrópolis, RJ: Vozes, 1982.

MAUSS, Marcel. Sociologia e Antropologia. Introdução de Claude Lévi-Strauss. São Paulo: Cosac e Naify, 2003.

RANCIÈRE, Jacques. Política da arte. Revista

Urdimento - Revista de Estudos em Artes Cênicas, n. 15 , out. 2010. 


\begin{tabular}{|c|c|}
\hline $\begin{array}{l}\text { Exchange and relation in } \\
\text { relational aesthetics }\end{array}$ & $\begin{array}{l}\text { Intercambio y relación en la } \\
\text { estética relacional }\end{array}$ \\
\hline $\begin{array}{l}\text { Abstract } \\
\text { This paper proposes a reflection on relational } \\
\text { aesthetics, developed in the } 90 \text { s by the French critic } \\
\text { and curator Nicolas Bourriaud. To this end, elects as } \\
\text { a counterpoint Marcel Mauss' thought, specifically } \\
\text { his essay on the gift, in order to understand the } \\
\text { similarities and differences between the approaches } \\
\text { of the two authors to the concepts of relationship and } \\
\text { exchange. The question that motivates this text is well } \\
\text { prepared: sociability models proposed by Bourriaud } \\
\text { reinforce and reproduce the logic of consumer } \\
\text { capitalism or suggest alternatives to it? } \\
\text { Keywords } \\
\text { Relational Aesthetics. Contemporary Art. } \\
\text { Models of Sociability. Sociology of Art. }\end{array}$ & $\begin{array}{l}\text { Resumen } \\
\text { Este artículo propone una reflexión sobre la estética } \\
\text { relacional, desarrollada en los años } 90 \text { por el crítico y } \\
\text { comisario francés Nicolas Bourriaud. Para ello, se elige } \\
\text { como contrapunto el pensamiento de Marcel Mauss, } \\
\text { específicamente su ensayo sobre el don, con el fin } \\
\text { de comprender las diferencias y similitudes entre los } \\
\text { enfoques de los dos autores a los conceptos de relación } \\
\text { e intercambio. La pregunta que motiva este texto es: } \\
\text { los modelos de sociabilidad propuestos por Bourriaud } \\
\text { refuerzan y reproducen la lógica del capitalismo de } \\
\text { consumo o sugieren alternativas a la misma? } \\
\text { Palabras-Clave } \\
\text { Estética relacional. Arte Contemporáneo. } \\
\text { Sociabilidad Modelos. Sociología del Arte. }\end{array}$ \\
\hline
\end{tabular}




\section{Expediente}

A revista E-Compós é a publicação científica em formato eletrônico da Associação Nacional dos Programas de Pós-Graduação em Comunicação (Compós). Lançada em 2004, tem como principal finalidade difundir a produção acadêmica de pesquisadores da área de Comunicação, inseridos em instituições do Brasil e do exterior.

\section{E-COMPÓS I www.e-compos.org.br I E-ISSN 1808-2599}

Revista da Associação Nacional dos Programas

de Pós-Graduação em Comunicacão.

Brasília, v.16, n.3, set./dez. 2013

A identificação das edições, a partir de 2008

passa a ser volume anual com três números.

\section{CONSELHO EDITORIAL}

Afonso Albuquerque, Universidade Federal Fluminense, Brasil Alberto Carlos Augusto Klein, Universidade Estadual de Londrina, Brasil Alex Fernando Teixeira Primo, Universidade Federal do Rio Grande do Sul, Brasil Ana Carolina Damboriarena Escosteguy, Pontifícia Universidade Católica do Rio Grande do Sul, Brasi

Ana Gruszynski, Universidade Federal do Rio Grande do Sul, Brasil Ana Silvia Lopes Davi Médola, Universidade Estadual Paulista, Brasil André Luiz Martins Lemos, Universidade Federal da Bahia, Brasil Ângela Freire Prysthon, Universidade Federal de Pernambuco, Brasil Antônio Fausto Neto, Universidade do Vale do Rio dos Sinos, Brasil Antonio Carlos Hohlfeldt, Pontifícia Universidade Católica do Rio Grande do Sul, Brasil Antonio Roberto Chiachiri Filho, Faculdade Cásper Líbero, Brasil Arlindo Ribeiro Machado, Universidade de São Paulo, Brasil Arthur Autran Franco de Sá Neto, Universidade Federal de São Carlos, Brasil Benjamim Picado, Universidade Federal Fluminense, Brasil César Geraldo Guimarães, Universidade Federal de Minas Gerais, Brasil Cristiane Freitas Gutfreind, Pontifícia Universidade Católica do Rio Grande do Sul, Brasil Denilson Lopes, Universidade Federal do Rio de Janeiro, Brasi Denize Correa Araujo, Universidade Tuiuti do Paraná, Brasi Edilson Cazeloto, Universidade Paulista , Brasil

Eduardo Peñuela Cañizal, Universidade Paulista, Brasil

Eduardo Vicente, Universidade de São Paulo, Brasi

Eneus Trindade, Universidade de São Paulo, Brasi

Erick Felinto de Oliveira, Universidade do Estado do Rio de Janeiro, Brasi

Florence Dravet, Universidade Católica de Brasília, Brasi

Francisco Eduardo Menezes Martins, Universidade Tuiuti do Paraná, Brasil

Gelson Santana, Universidade Anhembi/Morumbi, Brasi

Gilson Vieira Monteiro, Universidade Federal do Amazonas, Brasil

Gislene da Silva, Universidade Federal de Santa Catarina, Brasil

Guillermo Orozco Gómez, Universidad de Guadalajara

Gustavo Daudt Fischer, Universidade do Vale do Rio dos Sinos, Brasil Hector 0spina, Universidad de Manizales, Colômbia

Herom Vargas, Universidade Municipal de São Caetano do Sul, Brasi leda Tucherman, Universidade Federal do Rio de Janeiro, Brasil

Inês Vitorino, Universidade Federal do Ceará, Brasil

Janice Caiafa, Universidade Federal do Rio de Janeiro, Brasil

Jay David Bolter, Georgia Institute of Technology

Jeder Silveira Janotti Junior, Universidade Federal de Pernambuco, Brasil João Freire Filho, Universidade Federal do Rio de Janeiro, Brasil
John DH Downing, University of Texas at Austin, Estados Unidos

José Afonso da Silva Junior, Universidade Federal de Pernambuco, Brasi José Carlos Rodrigues, Pontifícia Universidade Católica do Rio de Janeiro, Brasil José Luiz Aidar Prado, Pontifícia Universidade Católica de São Paulo, Brasil José Luiz Warren Jardim Gomes Braga, Universidade do Vale do Rio dos Sinos, Brasil Juremir Machado da Silva, Pontifícia Universidade Católica do Rio Grande do Sul, Brasil Laan Mendes Barros, Universidade Metodista de São Paulo, Brasi Lance Strate, Fordham University, USA, Estados Unidos Lorraine Leu, University of Bristol, Grã-Bretanha Lucia Leão, Pontifícia Universidade Católica de São Paulo, Brasil Luciana Panke, Universidade Federal do Paraná, Brasil Luiz Claudio Martino, Universidade de Brasília, Brasi Malena Segura Contrera, Universidade Paulista, Brasil

Márcio de Vasconcellos Serelle, Pontifícia Universidade Católica de Minas Gerais, Brasil Maria Aparecida Baccega, Universidade de São Paulo e Escola Superior de Propaganda e Marketing, Brasi

Maria das Graças Pinto Coelho, Universidade Federal do Rio Grande do Norte, Brasil Maria Immacolata Vassallo de Lopes, Universidade de São Paulo, Brasil Maria Luiza Martins de Mendonça, Universidade Federal de Goiás, Brasil Mauro de Souza Ventura, Universidade Estadual Paulista, Brasil

Mauro Pereira Porto, Tulane University, Estados Unidos

Nilda Aparecida Jacks, Universidade Federal do Rio Grande do Sul, Brasi Paulo Roberto Gibaldi Vaz, Universidade Federal do Rio de Janeiro, Brasi Potiguara Mendes Silveira Jr, Universidade Federal de Juiz de Fora, Brasi Renato Cordeiro Gomes, Pontifícia Universidade Católica do Rio de Janeiro, Brasil Robert K Logan, University of Toronto, Canadá Ronaldo George Helal, Universidade do Estado do Rio de Janeiro, Brasil Rosana de Lima Soares, Universidade de São Paulo, Brasi Rose Melo Rocha, Escola Superior de Propaganda e Marketing, Brasil Rossana Reguillo, Instituto de Estudos Superiores do Ocidente, Mexico Rousiley Celi Moreira Maia, Universidade Federal de Minas Gerais, Brasi Sebastião Carlos de Morais Squirra, Universidade Metodista de São Paulo, Brasil Sebastião Guilherme Albano da Costa, Universidade Federal do Rio Grande do Norte, Brasil

Simone Maria Andrade Pereira de Sá, Universidade Federal Fluminense, Brasi Tiago Quiroga Fausto Neto, Universidade de Brasília, Brasil Suzete Venturelli, Universidade de Brasília, Brasil Valerio Fuenzalida Fernández, Puc-Chile, Chile

Veneza Mayora Ronsini, Universidade Federal de Santa Maria, Brasi Vera Regina Veiga França, Universidade Federal de Minas Gerais, Brasil

COMISSÃO EDITORIAL

Adriana Braga I Pontifícia Universidade Católica do Rio de Janeiro, Brasil

CONSULTORES AD HOC

Adriana Amaral, Universidade do Vale do Rio dos Sinos, Brasil

Alexandre Rocha da Silva, Universidade Federal do Rio Grande do Sul, Brasi

Arthur Ituassu, Pontifícia Universidade Católica do Rio de Janeiro, Brasil

Bruno Souza Leal, Universidade Federal de Minas Gerais, Brasil

Elizabeth Bastos Duarte, Universidade Federal de Santa Maria, Brasil

Francisco Paulo Jamil Marques, Universidade Federal do Ceará, Brasi

Maurício Lissovsky, Universidade Federal do Rio de Janeiro, Brasi

Suzana Kilpp, Universidade do Vale do Rio dos Sinos, Brasil

Vander Casaqui, Escola Superior de Propaganda e Marketing, Brasil

EDIÇÃO DE TEXTO E RESUMOS I Susane Barros

SECRETÁRIA EXECUTIVA I Juliana Depiné

EDITORAÇÃO ELETRÔNICA I Roka Estúdio

TRADUÇÃ̃o I Sieni Campos
COMPÓS I www.compos.org.br

Associação Nacional dos Programas de Pós-Graduação em Comunicação

Presidente

Eduardo Morettin

Universidade de São Paulo, Brasil

eduardomorettin@usp.br

Vice-presidente

Inês Vitorino

ines@ufc.br

Secretária-Geral

Gislene da Silva

Universidade Federal de Santa Catarina, Brasi

gislenedasilva@gmail.com
Universidade Federal do Ceará, Brasil 